\title{
ПСИХОСОЦИАЛЕН РИСК ЗА ЗДРАВЕТО ПРИ РАБОТА - МЕТОД ЗА ОЦЕНКА
}

\author{
Б. Ценова
}

\section{PSYCHOSOCIAL HEALTH RISK AT WORK - ASSESSMENT}

\author{
B. Tzenova
}

Рез юме. Поради повишения здравен риск психосочиалните фактори и методите за оиенката им са сред изследователските топ приоритети в областта на здравето и безопасността при работа. Целта на материала е да представи комплексен въпросник с няколко раздела (авторска разработка) за широко ползване от практиците в областта на ЗБР. Приведена е анкетна карта за оченка на психосоциалния риск за здравето при работа, адаптирана и валидирана в много изследвания при различни професионални групи в течение на 20 г. Основните модули са: независими величини -общи характеристики на натоварването, психосоциални характеристики и стресори, и зависими от тях характеристики на благосъстоянието (здравни оплаквания, удовлетвореност), както и предложения за подобрения към работодател. Онагледени са резултатите от конкретни изследвания и обработка на данните по модули. Методът се доказа като икономичен, и надежден инструмент, позволяващ, диференцирането на различни професии и работни места.

$\boldsymbol{S} \boldsymbol{u} \boldsymbol{m} \boldsymbol{m}$ a ry. Because of the increased health risk, psychosocial factors and their assessment methods are among the top research priorities for the health and safety at work. The purpose is to present a complex questionnaire with several sections (author's work) for wide use by practitioners in the field of HSW. A questionnaire was developed to assess the psychosocial health risk at work, adapted and validated in many studies in different professional groups over the course of 20 years. The main modules are: independent factors - general load characteristics, psychosocial characteristics and stressors, and dependent outcomes (health complaints, job satisfaction) as well as suggestions for improvements to an employer. Illustrated are some research results and data processing by modules. The method has proven to be an economical and reliable tool to differentiate between different professions and jobs.

Key words: psychosocial work factors, occupational stressors, occupational health, self-ratings, assessment methods

П слесвия на повишеното напрежение и стреса при работа са свързани с отсъствия, текучество, понижена производителност, и въпреки че е трудно да бъде изчислена точната им цена, те се оценяват на няколко стотин милиарда долара годишно [1]. Поради тези социални и икономически причини, изследвания с цел разкриване и разбиране на условията на работа, които допринасят за възникването на проблеми с физическото и психично здраве, заслужават да са във фокуса на специалистите и предмет на интензивно внимание и действия както и разработката и валидацията на кратки и надеждни, достьпни методи за разкриване на източниците на напрежение, рискови за здравето на работещите в различни работни среди.

\section{3Араве и безопасност при работа и психосоциален риск}

Експертна прогноза за актуалните психосоциални рискове свързани с безопасността и здравето при работа [2] показва, че от 1990 г. интензивността на труда се увеличава в много Европейски страни, както и в други развити страни. Тя е свързана с по-висок темп на работа и по този начин увеличава физическото и/ или умствено натоварване и вероятността от развитието на стрес и мускулно-скелетни заболявания, както и от увеличаване на злополуките и нараняванията при работа. Моралното онеправдаване на работното място също допринася за тези увеличени емоционални изисквания и натоварване [3]. Във връзка с професионалното здраве (ЗБР) психосоциалните фактори са сред изследователските топ приоритети, като се набляга на следните области [2]: (1) създаване на положителна работна среда за превенция на появата на психосоциални проблеми; (2) психосоциален риск свързан с организационните промени и разбиране на причините за последствия за здравето, които могат да бъдат свързани с тях, като напр. сърдечно-съдовите заболявания; (3) взаимодействие на психосоциалните рискови фактори и мускулно-скелетните симптоми и заболявания (МСУ), проблем за редица страни - ЕС, САЩ, Канада. То е индикатор за влошаване на здравето, често в резултат от комбинацията на на- растващите интензификация на труд, дял на монотонната работа и на повтарящите се задачи, както и лоша организация на труда, неадекватно от гледна точка на ергономичните изисквания работно оборудване и свързан с работата стрес. Промени в организацията на труда и трудовите договори, повишените изисквания за гъвкавост и мобилност затрудняват постигане на достоен баланс работа-бит с последващ стрес и здравни проблеми за работниците. В Европа като цяло тези проблеми са най-разпространени в югоизточна Европа.

В този „нов” свят на труда хората работят в условията на високи емоционални изисквания, често с прикрити трудности при справянето с тях и страх от загуба на работното си място, източник на допълнителен стрес. Проблемът е предмет на растящо безпокойство, особено в разширяващи се сектори където конкуренцията се засилва като здравеопазването и услугите.

С цел оценка на психосоциалния риск за здравето при работа в началото на 1990 г. съставихме комплексен въпросник с няколко раздела (авторска разработка), първоначално за изследването на натоварването и професионалния риск при учителите $[4,5,6]$, впоследствие допълван и многократно модифициран (разширяван или съкращаван) според изследователските цели и професионални групи* и достиженията на професионалната здравна психология. Основните модули, доказани като "работещи“" в многобройни проекти [7-15] са представени по-долу за широко ползване от практиците в областта на ЗБР.

\section{Анкетна карта за опредемяне на психосоциалния риск за зАравето при работа}

Използваната анкетна карта е резултат от многобройни наши изследвания * от 1991 г. насам, модифицирани на базата на теорията за организационния стрес [16], резултатите от изследванията на European Foundation [17] и собствените ни резултати. През 2008 г. по инициатива на тогавашен Зам. директор на НЦОЗА тя бе обсъдена на разширен колегиум от различни специалисти, които предварително бяха запознати 
с анкетата. Оттогава тя се използва широко в различни изследвания в НЦОЗА и външни организации (напр. [18]).

Структура - Анкетната карта включва като основни раздели общи демографски характеристики - данни за възраст, трудов стаж, пол, дльжност, направление/отдел, семейно положение, характеристики на трудовото натоварване, физическите и психосоциални условия на работата като независими величини - раздел I - отчасти, II и III; характеристики на общото здраве и благосъстоянието - зависими променливи - раздел I - отчасти, раздел IV, и предложения за подобрение.

тики;

- Обща част - социално-демографски характерисличини:

- Характеристики на работата като независими ве-

- общи черти на работата (21 въпроса) - натоварване, темп на работа, смени - раздел I. Психосоциалното натоварване често се асоциира с начина, по който е организиран самият труд, т.е. от условията на труд, професионалните отговорности, съдържанието на труда, работния график.

- психосоичилни характеристики на работа (18 въпроса) - раздел II. Социалните взаимодействия на работното място могат да бъдат източник на стрес. Взаимодействия с колеги/работна група - адекватната социална подкрепа има защитна роля от негативните влияния на стреса. Съществуват много изследвания относно ефективния стил на ръководство и неговото влияние върху работещите.

- източници на стрес и напрежение при работа (21-23 въпроса) - раздел III. Стресьт на работното място може да бъде причинен от множество изисквания - стресори на работната среда като: недостатьчно време за завършване на работната задача; липса на точна и ясна трудова характеристика; липса на дискусии по проблеми свързани с работата; некооперативен пряк ръководител и/или колеги; липса на контрол; неудовлетвореност от работа; липса на сигурност на работното място; дискриминация по пол, възраст, етнос и др.; опасни условия на труд; невъзможност за професионално израстване и др.

Освен приложената анкета, други диференциращи методи апробирани у нас са адаптираните версии на немския въпросник FIT за изисквания на работата по отношение на интензивност на натоварването и степени на свобода (самоопределяне) в работата $[19,20]$, както и въпросникът на Спилбъргър за честота и интензивност на 30 често срещани на работа стресора.

- Характеристики на благосъстоянието - зависими променливи - раздел IV.

Професионалният стрес вследствие на взаимодействие между характеристиките на работещия и на самата професия, нарушава състоянието на психично или физиологично равновесие (хомеостаза). Външните фактори са професионални стресори, а нарушената индивидуална хомеостаза - професионално обусловено напрежение с пет измерения:

- краткотрайни субективни състояния (тревожност, напрегнатост, гняв)

- продължителни, хронични реакции (депресия, недобро физическо състояние)

- преходни физиологични промени (биохимия, кръвно налягане и др.)

- влошено соматично здраве (стомашно-чревни смущения, сърдечно-съдови заболявания и др.)

- намаляване на работоспособността и ефективността на работата.

Психосоматични здравни оплаквания, вкл. мускулно-скелетни в различни области на тялото, за последните 6 месеца, както и посещение на лекар и лечение поради някои от отбелязаните причини (20 въпроса),

Удовлетвореност от работата - 1 общ въпрос, идея за търсене на друга работа и напускане на сегашната. Методиката е апробирана при учители, персонал от социалноздравни заведения, медицински сестри, лекари и санитари, академичен персонал, инженери и други.

Според целите и обхвата на изследването се прилагат и други, по-диференцирани методики за сравнителния анализ на различните аспекти на неудовлетвореността от работата $[20]$.

- Предложения за подобрения - последен раздел в анкетната карта.

В анкетната карта е дадена възможност изследваните работещи да дадат своите предложения за подобрения на здравословните и безопасни условия на труд, които могат да бъдат направени от непосредствения ръководител и работодателя или от самите тях.

\section{Провеждане на изследването и представителност}

Анкетите са анонимни, раздават се индивидуално по сектори и отдели, попълват се в удобно за всеки работещ/служител време с предварително уговорен срок до 1-2 дена в зависимост от конкретния сменен график. За удовлетворяване на изискването за анонимност събирането на анкетите се извършвано лично от член на изследователския екип или се предава в запечатан плик на предварително сьгласувано лице за контакт и съдействие (охрана на труда, представител на работещите). Допълнителна информация за планиране, особености и промени в действащите работни графици се събира с уговореното съдействие на съответните завеждащ отдели/сектори и специалиста по безопасност и охрана на труда. Оценка на представителността на получената информация може да се направи въз основа на информацията за процента на участвалите в анонимната анкета служители спрямо общия брой. При критерий над $50 \%$ участвали, резултатите от анкетата следва да се считат за представителни.

\section{Статистическа обработка}

В съответствие с поставената задача за обработката на събраните данни се прилагат честотен, вариационен и дисперсионен анализ по видове отговори на отделните въпроси в зависимост от работното място/отдел, пол, възраст, длъжност и общо за изследвания контингент. Много посилно от сравнения по групи въз основа на длъжностните характеристики, се откроява влиянието на характера и съдържанието на труда и изискванията в отделните професионални групи и направления, отличаващи се и с характерен режим на работа и съдържание на изискванията на работата и натоварването.

Допълнително с помощта на многомерни анализи се разкриват взаимовръзките между различни характеристики на работата, здравните оплаквания, умора, доминирани от организационния климат в организацията взаимоотношения. Могат да се определят и прогностични по отношение на здравето фактори на работната среда при коректно прилагане на статистическите изисквания и критерии, често пренебрегвани от практиците.

\section{Резултати и примери от наши и чужди емпирични изследвания}

Санитарно-хигиенни фактори като състояние на въздуха в работното помещение, шум, сменен режим на работа и работна поза заемат първите места сред посочените стресори в работата след неадекватното възнаграждение, посочвано като водещ източник на напрежение в различни 
професионални групи при изследвания на НЦООЗ и синдикатите през последните 20 години в страната $[10,21]$.

В случаите, когато липсва контрол на собствената дейност в комбинация с повишени изисквания, нереализирани очаквания, ролеви конфликти и липса на социална подкрепа, повечето работещи са тревожни, депресирани, отчуждени (Фихура 1). Модельт на Karasek [1] за изискванията на работата и възможностите за контрол и автономия е широко разпространен като модел за професионален стрес. Особено внимание се отделя на степента на свобода и избор, които има работещият при вземане на решение в отговор на изискванията на професията и работната среда $[19,22,23]$.

Следва да се има предвид, че несигурността на работното място, заплащането на труда и съкращенията в една организация водят до сериозни проблеми с мотивацията и благополучието на работещите. Работещите в предприятие, в което се провежда реорганизация се два пъти повече изложени на стрес, в сравнение с тези, в чиито предприятия такава не се провежда.

Фигура 1. Изразеност на психосоциалните условия и натоварване на работното място в две организации в здравеопазването и при инженерно-технически персонал в масмедия (в \%, брой изследвани във всяка извадка от 160 до 169)

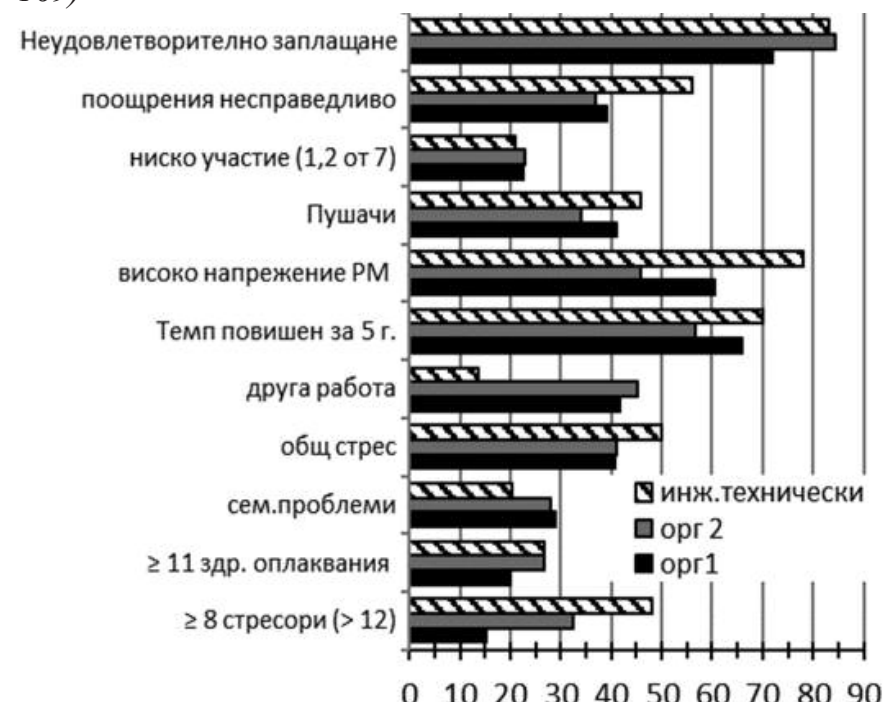

Сравнителното изследване показва, че на практика преживяванията на новопостъпилите са сходни с тези, типични за по-възрастните и опитни работници (например социални стресори, количествено претоварване, проблеми на сътрудничеството) и че както на работното място, така и в личния живот доминират социалните стресори [24]. Ето как хроничните състояния представляват фонови променливи, които не само влияят силно върху благосъстоянието, но също така и върху непосредствената реакция при сбльскване със стресори.

Изследването на технически-артистичен персонал от масмедия (168 служители, 2006) разкрива, че водещите сред 23 източника на напрежение са следните стресори [11]:

- Състояние на въздуха $(70.9 \%)$

- Работа с много хора $(66.7 \%)$

- Шум на работното място $(65.5 \%)$

- Сменен режим на работа (63.6\%)

- Работна поза, повече седнал $(57.7 \%)$ $(56.4 \%)$

- Липса на признание за добре свършена работа

- Недостатъчно време за задоволително изпълнение на работата (46.1\%)
- Много отговорности, малко правомощия за вземане на решения $(38.8 \%)$

- Полагане на извънреден труд (33.3\%)

- Неизправни и опасни съоръжения (29\%).

Условията на труд, като силен шум, лошо проветряване/осветление, твърде висока и/или ниска температура могат да доведат не само до физически проблеми, но и да повлияят негативно на психичното здраве на работещите.

Таблица 1. Процентно разпределение на здравните оплаквания при различни групи болничен персонал и инженернотехнически персонал от масмедия

\begin{tabular}{|c|c|c|c|c|c|}
\hline $\begin{array}{r}\text { Чести здравни оплаквания } \\
\text { през последните } 6 \text { месеца } \\
\text { Брой изследвани лица } \\
\end{array}$ & \begin{tabular}{|c|} 
Хирур- \\
гични \\
cecmpu \\
$88^{*}$ \\
\end{tabular} & \begin{tabular}{|c|} 
МБАЛ \\
cecmpu \\
133 \\
\end{tabular} & \begin{tabular}{|c|} 
МБАЛ \\
лекари \\
93 \\
\end{tabular} & \begin{tabular}{|l|} 
Меди- \\
цински \\
колеж \\
$301 ; 18$ \\
\end{tabular} & \begin{tabular}{|c|} 
ИТР \\
Macme- \\
дuя \\
168 \\
\end{tabular} \\
\hline Болки в гърба & - & 69 & 70 & 68.0 & 65.2 \\
\hline Болки в костите и мускулите & - & 66 & 57 & 63.6 & 70.1 \\
\hline Честа умора & $30.6^{*}$ & 52 & 58 & 56.1 & 57.3 \\
\hline $\begin{array}{l}\text { Болки в гъдите } \\
\text { област }\end{array}$ & 22.8 & 40 & 46 & 46.3 & 48.8 \\
\hline Виене на свят & 52.3 & 43 & 43 & 45.0 & 55.5 \\
\hline $\begin{array}{l}\text { Постоянно се тревожа за } \\
\text { много неща }\end{array}$ & 56.9 & 42 & 48 & 47.5 & 62.2 \\
\hline $\begin{array}{l}\text { По-често се изморявате от } \\
\text { очакваното } \\
\end{array}$ & & 43 & 45 & 43.6 & 47.6 \\
\hline Нарушения на съня & 26.1 & 47 & 43 & 44.5 & 62.8 \\
\hline Често главоболие & 35.6 & 38 & 30 & 38.5 & 34.5 \\
\hline $\begin{array}{l}\text { Боцкане в крайници, изтрът- } \\
\text { ване }\end{array}$ & $37.5 *$ & 41 & 25 & 38.2 & 46.9 \\
\hline $\begin{array}{l}\text { Равнодушие, безразличие } \\
\text { към всичко }\end{array}$ & $44.1 *$ & 36 & 32 & 34.3 & 39.7 \\
\hline $\begin{array}{l}\text { Тежест или подуване на } \\
\text { стомаха }\end{array}$ & 39.1 & 29 & 27 & 28.0 & 39.9 \\
\hline Парене, сълзене на очите & - & 22 & 24 & 24.8 & 54.9 \\
\hline Липса на настроение & 29.9 & 19 & 32 & 25.4 & 39.9 \\
\hline $\begin{array}{l}\text { Лекували ли сте се за тези } \\
\text { оплаквания? }\end{array}$ & - & 19 & 23 & 21.8 & 20.2 \\
\hline Търсене на лекарска помощ & - & 19 & 11 & 18.5 & 17.3 \\
\hline
\end{tabular}

Забележка. В таблицата са маркирани здравните симптоми съобщавани от повече от $40 \%$ от изследваните в отделните професионални извадки, а в курсив са отбелязани установените при повече от $50 \%$ от съответната извадка симптоми; * Използван е друг вариант на въпросника за здравни оплаквания, където съответните въпроси в посочения ред са: изтощение, болки в ръцете, и обща отпадналост.

Пораженията на здравето при работещи подложени на стресови въздействия включват напрежение, болки в мускулите (водещи, Таблица 1), стомашни проблеми, болки в областта на сърцето, проблеми с кръвното налягате, емоционално разстройство, сексуални проблеми. На рискови за МСУ фактори са експонирани от 17 до $46 \%$ от работещите в различни сектори в европейските страни. Психологичните ефекти от стреса включват когнитивни ефекти (удовлетвореност от труда, отегчение), афективни разстройства (тревожност, депресия) и соматични симптоми (главоболие, световъртеж, стомашно-чревни проблеми, и др. (Таблица 1). Стресът на работното място може да предизвика и някои негативни поведенчески навици като: тютюнопушене, прекомерна употреба на алкохол и храна, агресивно поведение. Повечето от тези стрес-реакции могат да бъдат началото на определено соматично заболяване.

Умората е едно от най-разпространените оплаквания сред трудоспособното население. Тя се определя като “промяна в механизма на психологическия контрол, регулиращ поведението при изпълнение на задачата, произтичаща от предшестващите психични и/или физически усилия, които до такава степен са отегчителни и еднообразни за индивида, поради което става невъзможно да бъдат посрещнати про- 
фесионалните изисквания или пък да бъдат посрещнати с цената на повишено ментално усилие и преодоляване на психичната съпротива. Хроничната умора силно повлиява нормалното функциониране на индивида и може да доведе до отсъствия и нетрудоспособност.

Предпоставка за социалните стресори на работното място (като конфликти или враждебност) са липсата на уважение или на признание, които са заплаха за Аз-а. [3, 25]. Стресът, предизвикан от такъв вид оскърбление и атака срещу личността, може след време да доведе до промяна на телесното тегло. Изследвания през последните години [26] убедително доказват, че увеличаване на социалните стресори и намаляване на контрола и автономността в работата през първата година от професионалния живот са предиктори на повишаване на индекса на телесната маса. Следователно, реорганизацията на работата с намаляване на социалните стресори на работното място и повишаване на контрола и автономността в работата, може да помогне за предотвратяване на епидемията от затлъстяване.

В резултат на последните достижения в областта на невронауките и поведенческата медицина става все по-ясно, че психичното функциониране е фундаментално свързано с физическото и социално функциониране и здравните резултати (27), както установяваме и в нашите изследвания.

\section{ИндивиАуамни разАичия, стрес и зАраве}

За работещите в някои професии жени е характерен по-висок риск за здравето в сравнение с мъжете поради някои психосоциални фактори [28]. Според изследването на Шведския Национален Регистьр такива професии са: повечето професии от материалната сфера, телефонните оператори, касиери, пощенски служители, професии използващи видеотерминали, медицински сестри, шивачки.

Индивидуалните различия по отношение както на професионален опит и конституция влияят върху нивата на изпитвания стрес на работното място, респективно и на физическото и психично здраве [5]. При интерпретация на резултатите от емпиричните изследвания трябва да се има в предвид, че: индивидите се различават по вероятността за среща със стресорите, в зависимост от тяхната социална среда, поведение, като някои от стресорите могат да се самогенерират (напр. конфликти с други хора се предизвикват от лоши социални умения или противопоставящо се поведение), както и по оценката на стресорите: напр. хората с ниска самооценка или високи бални оценки по чертата негативен афект не могат да оценят реално стресора, и да действат адекватно вследствие на което са по-стресирани. Хората се различават и по начина, по който се справят с трудностите и стреса (копинг-стратегии).

\section{Заключение}

Използваната Анкетна карта с основни модули за определяне и оценка на психосоциалния риск за здравето при работа се доказа в редица изследвания през последните десетилетия като икономичен, надежден и работещ инструмент за диференциране на източниците на напрежение и намалена работоспособност и свързаните с тях психосоматични проблеми. По този начин, търсенето на ресурси, както и интервенциите и стратегиите за управление на бъдещи рискове, могат да бъдат планирани по-добре и своевременно и да се повиши ефективността им.

Изследванията ни с представения метод разкриват, че субективните оценки на трудовото натоварване и самооценките на здравето, както и взаимовръзките им, са важни и надеждни крайни резултати в трудовохигиенните и социално-епидемиологични изследвания. Многобройни изследвания показват, че те влияят върху качеството на ежедневния живот, и че психосоциалната работна среда има далеко надхвърлящи работното място влияние върху психичното и физическо здраве, настроението, мотивацията [29]. Методът отговаря на приоритетите изтькнати в експертните оценки от потребност от изследвания и надеждни методи за идентификацията на водещите рискове при работа, насочени към ранно предвиждане с цел превенция на възможните им отрицателни ефекти за здравето и безопасността на работещите.

\section{Библиография}

1. Karasek RE., Theorell T. Healthy work: stress, productivity, and the reconstruction of working life. New York: Basic Books, 1990.

2. Brun E, Milczarek M. Expert forecast on emerging psychosocial risks related to occupational safety and health. EASHW: Luxembourg: Office for Official Publ of the EC, 2007.

3. Ценова Б. Насилие на работното място - актуален психосоциален и здравен проблем. Ръководство за превенция. Изд. НЦОЗА, София, 2017, 120 c., ISBN 978-954-8404-36-5

4. Ценова Б. и кол. Психологични фактори на труда и индивидуалнопсихологични характеристики като ресурси за самочувствието и психичното здраве. Тема 2.9 ДП, НЦХМЕХ, София, 1995. НАЦИД № 83745130

5. Ценова Б. Професионален стрес и психично здраве при учителите ч.І. Бълг. сп. по Психология, 1996, 4: 46-72.

6. Ценова Б. (ръковод.) и кол. Стрес и бърнаут при учители и медицински сестри. Отчет НЦХМЕХ, 1998, С., НАЦИД N. 84000179

7. Ценова Б., Иванович Е. Психично здраве и условия на труд при оперативен персонал от ВЕЦ. Хигиена и здравеопазване, 1995, 1, 9-13

8. Ценова Б., Велкова Д. и др. Професионални стресори и психично здраве при хирургични сестри. Проблеми на хигиената, XXIII, 2002, 3:3-8.

9. Ценова Б., Израел М., Топалова М., Данев С. Поведенчески и физиологични индикатори на стреса при електромагнитна експозиция в комуникацията. Сб. Стрес, С., КНСБ, 2003: 427-35.

10. Ценова Б. Стрес при работа - емпирични изследвания. В сб. “Да работим по проблема стрес", С., МТСП, ФУТ, ЕА БЗР, 2002: 82-101.

11. Ценова Б., Велкова Д. Субективно здраве, бърнаут и източници на стрес в работата на художествено-технически персонал. Бълг. Сп. По Психология, 2008, 1-4: 565-572.

12. Ценова Б. Характеристики на работата и благополучието при работещи в сферата на услугите. Бълг. Сп. по Обществено здраве, 2009, vol. I, 3: 51-65, ISSN 1313-6461

13. Ценова Б. Психосоциалните детерминанти на благополучието и психичното здраве при работа. В: «Приложна психология и социална практика», Варна, Унив. Изд-во ВСУ „Ч. Храбър”, 2010: 187-198, ISSN 1314-0507

14. Tzenova B. Psychosocial working conditions as health risk in civil servants sample. Bulgarian journal of Psychology, 2010, 1-4: 573-584, ISSN 08617813

15. Tzenova B. Workload and Stress Effects in Female Professions. Conference Proceedings "Education, Science, Innovations", ESI'13, EPU, Pernik, 2013, 181-90, ISSN 1314-5711

16. Cooper CL., ed. Theories of organizational stress. Oxford: Oxford University Press, 1998.

17. European opinion research group, Dublin 4, 2001, App. 3. Euro Foundation for the improvement of living and working conditions, 2003:120-36.

18. Сапунджиева М., и др. Въздействие на работната среда върху психоемоционалното състояние на специалистите с колежанско образование работещи в болнично заведение. В: „Здравеопазването през 21 век. Реалности и перспективи.” Изд. център МУ-Плевен, 2010, т.2, 608-10.

19. Frese M. Kontrolle und Taetigkeitsspielraum. In: S.Greif, H.Holling, N.Nicholson (Hsg.) Arbeits- und Organisationspsychologie. München, Psychologie Verlags Union, 1989.

20. Ценова Б. Неудовлетвореност от работата и бърнаут-симптоми при технически персонал от масмедия. В: сб. „Приложна психология и социална практика- ХІІ“, Унив. Изд. ВСУ „Ч. Храбър”, Варна, 2013: 461-77, ISSN 1314-05073

21. Христов Ж. Епидемиология на стреса при лекари и учители в периода на преход. Дисертация, София, 2004, 209 с

22. Bobak M., Pikhart H., Rose R., et al. Socioeconomic factors, material inequalities, and perceived control in self-rated health: cross-sectional data from seven post-communist countries. Soc Sci Med,2000, 51: 1343-1350.

23. Siegrist J. Adverse health effects of high-effort/low-effort conditions. J Occ Health Psychol,1996; 1: 27-41 
24. Grebner S., Elfering A., Semmer N. et al. Stressful Situations at Work and in Private Life among Young Workers: An Event Sampling Approach. Social Indicators Research, 2004, 67: 11-49. 10.1023/B:SOCI.0000007333. 96382.3a

25. Elovainio M., Kivimaki M., Vahtera J. Organizational Justice: Evidence of a New Psychosocial Predictor of Health. Am. J. Public Health, 2002, 92: $105-8$.

26. Kottwitz M., Grebner S., Semmer N., et al. (). Social Stress at Work and Change in Women's Body Weight. Industrial health ,2014, 52. 10.2486/ind health. 2013-0155.

27. Sparks K., Faragher B., Cooper C.L. Well-being and Occupational Health in the 21 st Century Workplace. J of Occup \& Organiz Psychology, 2001, 74(4): 489-509.

28. Hraba J., Lorenz F., Lee G., et al. Gender differences in health: evidence from the Czech Republic. Soc Sci Med, 1996,43:1443-51.

29. Miilunpalo S., Vuori I., Oja P., et al. Self-rated health status as a health measure: the predictive value of self-reported health status on the use of physician services and on mortality in the working-age population. J Clin Epidemiol, 1997, 50:517-28.
Проучване на водещите фактори на работната среда и тяхното въ3действие върху оператори от ВЕЦ (1991, ЦИНТИ ㅇ 83697045) и от ТУ “Софийски телефонни и телеграфни съобщения” (1991, ЦИНТИ № 83697029), изследване на психичното благосъстояние на учителите в зависимост от характеристики на работата им и личностните ресурси (ДЗ 160, НИХПЗ, 1991-1992, ЦИНТИ No 82283231). В Трудово-хигиенни проучвания на факторите на работната среда и професионалния риск за работници от прокатното производство (1993), влиянието на електромагнитни полета (ЕМП) в обекти на НУ „Радио и телевизионни станции“ (1992), Оценка на нервно-психичното натоварване и стрес свързан с работата: водещи психосоциални фактори като източници на напрежение и последствията им за благосъстоянието на: мениджърски и банков персонал (2002 г.) , при кадрови военнослужещи и военни служители (2002 г.) и на работещите в: М3 (2006 г), НЦОЗА (2007-2008 г.), художествено-технически персонал в масмедия (2006-2007 г.), персонал от социално-здравни заведения за деца и възрастни (20002003, 2006 г.).

\title{
РАЗВИТИЕ НА ЧОВЕШКИТЕ РЕСУРСИ В ЗДРАВЕОПАЗВАНЕТО - ИЗМЕРЕНИЕ И ПРЕДИЗВИКАТЕЛСТВА \\ М. Владимирова, Н. Данова, Пл. Димитров
}

\section{DEVELOPMENT OF HUMAN RESOURCE FOR HEALTHCARE - DIMENSION AND CHALLENGES}

\author{
M. Vladimirova, N. Danova, Pl. Dimitrov
}

Рез юме. Глобалната стратегия за човешките ресурси в здравеопазването през 2016 г. иели укрепване на капацитета на заетите в сектора. Тя е в унисон с поставените приоритети в иелите за устойчиво развитие относно подготовката и развитието на работната сила в здравеопазването, особено в по-слабо развитите страни. Продължава да се споделя острият дефицит на работната сила в здравеопазването, както и нарастващото несъответствие между потребностите на населението от търсене и предлагане на специалисти към момента и в бъдеще. В този доклад е направен кратък анализ на предвидените за иелта мерки в нашата страна.

S u m m a ry. Global Human Resources Strategy in healthcare in 2016 aims to strengthen the capacity of the sector's employees. It is in line with the priorities set in the sustainable development objectives on healthcare preparedness and development in health care, especially in the less-developed countries. The acute health deficit in the workforce, as well as the growing disparity between the needs of the population from demand and supply of specialists in the present and the future, continue to be shared. This report provides a brief analysis of the measures envisaged for this purpose in our country.

Key worlds: human resources, health care, problems

$\prod_{\text {cypc }}$ мографското измерение на проблема за човешките ресурси се свързва със застаряващо население и отчитане на застаряваща работна сила с недостатъчен брой млади специалисти, особено за основни специалности, които не са толкова привлекателни за тях. През последните години се наблюдава засилена миграция в рамките на ЕС и извън него. В приетата стратегия на СЗО (2013 г.) и Резолюция, в която основен акцент е образованието и квалификацията на медицинските кадри, за да се подпомогне постигането на крайната цел за универсален достъп до здравеопазване. [13, 15] За целта се разработват политики, стратегии, планове, касаещи обучението и квалификацията на специалистите на базата на цялостна оценка и подготовка на кадрите като се използват подходящи инструменти. Предлагат се поредица от мерки и в нашата страна като: изпълнение на приетите цели на хилядолетието, осъвременяване на методологията, преодоляване на консерватизма, прилагане на комплексен подход, въвеждане на мерки за превенция на негативни фактори. [1] Анализът на актуалното състояние на работната сила в здравеопазването извежда на преден план специфични проблеми като: съществуваща международна миграция, необходимост от изработване на международни правила и норми, прилагане на мерки за превенция на риска от миграция, включително и за страните с по-слаб ръст на икономика и дефицит на кадри, както и защита на правата на тези специалисти.

На този етап е необходима промяна в политиките, след критичен ситуационен анализ, ясна визия с ключови цели в националната здравна стратегия на Р. България. Дейностите в областта на общественото здраве у нас се разглеждат като се имат предвид общите изисквания, които се поставят към човешките ресурси във всяка страна. Те включват необходимостта от планиране, обучение, постоянна квалификация, организация на труд, заплащане, мотивация, удовлетвореност и др. В Таблицата са посочени основните заинтересовани страни при планиране на човешките ресурси у нас: 